\title{
A ABORDAGEM COGNITIVA DA METÁFORA EM PERSPECTIVA PRAGMÁTICA NOS SÉCULOS DEZOITO E DEZENOVE: AS CONTRIBUIÇÕES DE LAMBERT E WEGENER A DISCUSSÕES ATUAIS
}

Ulrike Agathe SCHRÖDER*

- RESUMO: Desde o surgimento da Teoria Conceptual da Metáfora, há mais de trinta anos, houve uma série de autores que apontaram a falta de contextualização historiográfica, uma vez que a maioria das hipóteses sobre a metáfora conceptual e até boa parte dos exemplos já são antecipadas desde o século dezessete em reflexões filosóficas, antropológicas, psicológicas e linguísticas. O presente trabalho pretende apresentar dois pensadores dos séculos dezoito e dezenove, a saber, o filósofo Johann Heinrich Lambert (1965) e o linguista Philipp Wegener (1991), que não apenas já desenvolvem uma teoria cognitiva da metáfora cotidiana, como também já conseguem integrar aspectos pragmáticos, que atualmente são redescobertos como fatores descuidados pela primeira geração da Linguística Cognitiva. Sendo assim, as duas concepções podem lançar uma ponte a discussões atuais, uma vez que ambas conseguem apontar caminhos para superar tanto o abismo entre o sujeito solipsista e a sociedade, como a dicotomia entre universalismo e relatividade cultural. Os dois autores entendem a metáfora como fenômeno cognitivo e, ao mesmo tempo, intersubjetivo, por ser negociado entre os participantes em situações comunicativas concretas.

- PALAVRAS-CHAVE: Metáfora conceptual. Linguística Cognitiva. Pragmática. Lambert. Wegener.

\section{Introdução}

Desde o surgimento da Teoria Conceptual da Metáfora (TCM) há mais de trinta anos (LAKOFF; JOHNSON, 1980, 1999), houve uma série de autores que apontaram o ecletismo contínuo da abordagem pela falta de uma contextualização historiográfica (SCHMITZ, 1985; HÜLZER-VOGT, 1987; JÄKEL, 2003; CHAMIZO DOMINGUEZ; NERLICH, 2010; SCHRÖDER, 2004, 2008, 2010a, 2012a), uma vez que a maioria das hipóteses sobre a metáfora conceptual e até boa parte dos exemplos já foram debatidas a partir do século dezessete em reflexões filosóficas (Clauberg, Vico, Locke, Leibniz, Lambert, Kant, Nietzsche, Mauthner, Vaihinger, Richards, Blumenberg), antropológicas (Herder, Boas, Sapir, Whorf, Gehlen), psicológicas (Stählin, Bühler) e linguísticas (Paul, Wegener, Gerber, Biese, Lady

* UFMG - Universidade Federal de Minas Gerais. Faculdade de Letras. Belo Horizonte - MG - Brasil. 31270-901 schroederulrike@gmx.com 
Welby, Black, Weinrich). Todos esses autores apresentam plena consciência da função cognitivo-epistêmica da metáfora, do seu caráter onipresente na fala cotidiana e de sua atuação tanto no nível da conceitualização quanto no nível da língua.

Com o presente trabalho, pretende-se apresentar dois pensadores dos séculos dezoito e dezenove, a saber, o filósofo Johann Heinrich Lambert (1965a, 1965b) e o linguista Philipp Wegener (1991), que não apenas já desenvolvem uma teoria cognitiva da metáfora cotidiana, como também já conseguem integrar aspectos pragmáticos, que atualmente são redescobertos como fatores descuidados pela primeira geração da Linguística Cognitiva (CAMERON, 2007; STEEN, 2007; TENDHAL; GIBBS, 2008; SCHRÖDER, 2012a).

Como fio condutor para elaborar uma discussão sobre as ligações entre a TCM e as teorias desses dois autores, recorrer-se-á às nove hipóteses de Jäkel (2003), que as formula para comprimir o núcleo da Teoria Conceptual da Metáfora (LAKOFF; JOHNSON, 1980, 1999). Segundo ele, a TCM compõe-se das seguintes suposições:

1. Ubiquidade:A metáfora não é uma exceção da criatividade poética ou da retórica;

2. Domínio: Metáforas não podem ser vistas isoladamente, mas conceitualmente. Tais conceitos interligam dois domínios (fonte e alvo) via mapeamento;

3. Modelo: Metáforas conceptuais formam modelos cognitivos com estruturas da organização do conhecimento. Elas radicam-se em experiência corporal (realismo corporificado);

4. Diacronia: Estudos sobre o desenvolvimento histórico de metáforas conceptuais revelam mudanças de pensamento;

5. Unidirecionalidade: A relação entre o domínio-fonte e o domínio-alvo não é reversível;

6. Invariância: Os esquemas que são transferidos a um novo domínio não são modificados;

7. Necessidade: A metáfora tem três funções básicas: ela serve para a explicação, compreensão e exploração do mundo social;

8. Criatividade:A metáfora é aberta para inúmeros novos caminhos de pensamento;

9. Focalização: A descrição da metáfora é parcial. Ela destaca certos aspectos do domínio-alvo e esconde outros. 


\section{Johann Heinrich Lambert e sua ótica dupla sobre a metáfora}

Já estabelecendo questões semióticas no século dezoito, para o filósofo Lambert, cujo interesse em problemas epistemológicos o torna um precursor significativo da teoria crítica do reconhecimento de Kant, a metáfora representa o tropus mais importante. Ele dirige sua atenção à sua função dupla, isto é, a metáfora, para ele, é ferramenta de reconhecimento e comunicação unidamente, pois é só por meio dela que a impressão que os objetos deixam no homem se torna apreensível: o abstrato torna-se formulável e, ao mesmo tempo, comunicável (LAMBERT, 1965b). Desse modo, Lambert escolhe o caminho da impressão para chegar a uma posição crítica da língua com relação à sua função cognitiva. Paralelamente, ele aprofunda algumas ideias sobre os mecanismos comunicativos e condutores da língua de forma que sua discussão se revela fértil face a discussões atuais.

O ponto de partida para sua semiótica é a diferenciação entre o necessário (dem Notwendigen), o arbitrário (dem Willkürlichen) e o hipotético (dem Hyothetischen) da língua. Ungeheuer (1979) concebe esta terminologia particular como introdução implícita das perspectivas comunicativa e extracomunicativa acerca do fenômeno da língua, ${ }^{1}$ uma vez que Lambert se refere com o termo "o necessário" à relação representacional entre signo e conceito, com o termo "o arbitrário" aos significados dos signos em si, ou seja, ao significado convencional, e com o termo "o hipotético" à prática comunicativa, ao processo em si, que é guiado pelas hipóteses sobre os significados e o sentido da fala como foram estabelecidos pelos respectivos interlocutores. Enquanto o aspecto arbitrário corresponde a um tratamento extracomunicativo dos meios linguísticos, dedicando-se à análise do sistema, o aspecto hipotético aponta para o manejo comunicativo, e se refere "[...] aos atos comunicativos linguísticos e ao problema prático envolvido na maneira como seriam atingidas a compreensão recíproca e a correspondência entre o significado da palavra e o sentido da fala.". (UNGEHEUER, 1979, p.98, tradução nossa).

Lambert (1965a, p.483, tradução nossa) vê a motivação para a comparação que a metáfora realiza na "[...] semelhança da impressão que as sensações dos

\footnotetext{
Ungeheuer (2004) introduz a distinção entre perspectiva comunicativa e extracomunicativa, por um lado, com base na filosofia fenomenológica, recorrendo à distinção de "Zuhandenem" (estar à disposição) e "Vorhandenem" (ser existente) de Heidegger (1957) e à diferença entre "fungierend" (funcionando) e "thematisierend" (tematizando) de Husserl (1921). Por outro lado, Ungeheuer segue a abordagem linguística de Bühler (1982), que separa entre teorias sobre língua como ato e como formação, fundamento para uma perspectiva funcionalista do falar, ligada ao sujeito, e uma perspectiva do objeto, desligada do sujeito (BÜHLER, 1932). Bühler, por sua vez, estabelece sua abordagem recorrendo aos conceitos "Ergon" e "Energeia", de Humboldt, e "Langue" e "Parole", de Saussure, embora sua dicotomia não coincida com estas duas diferenciações. Com relação à história do problema, veja Kolb (2010).

2 No original: "[...] auf die sprachlichen Kommunikationsakte und auf das darin enthaltene praktische Problem, wie gegenseitiges Verständnis und Übereinstimmung in Wortbedeutung und Redesinn zu erreichen sei."
} 
objetos externos e a imaginação dos objetos abstratos e invisíveis provocam em nós." ${ }^{3} \mathrm{~A}$ onipresença da metáfora indica sua função indispensável de procedimento linguístico da comunicação (UNGEHEUER, 1980). Assim que uma expressão metafórica é aceita pelos interlocutores, inicia-se o processo da habituação (HÜLZER-VOGT, 1987). Com isso, para Lambert, pode-se observar que as diferentes instâncias do nível linguístico estão ligadas a um princípio cognitivo que está por trás das palavras:

Muito pelo contrário, já foi introduzido há muito tempo que nós comparamos o visível com o invisível, o mundo corporal com o mundo intelectual, as emoções com os pensamentos, usando para ambos as mesmas palavras e expressões. Com isso, as palavras necessariamente recebem um significado duplo e até, às vezes, múltiplo. Ter uma luz no quarto, e ter luz nos pensamentos apresentam tais formas da fala. ${ }^{4}$ (LAMBERT, 1965a, p.483, tradução nossa).

Tal antecipação da metáfora conceptual unDERSTANDING IS SEEING e dos esquemaS imagéticos CONTÊINER, CAMINHO e FORÇA (LAKOFF; JOHNSON, 1980, 1999), que Lambert tematiza logo após esta citação, aponta a suposição implícita da Hipótese do Domínio (2), ainda mais sendo que ele recorre ao princípio semântico da polissemia das palavras, cuja base, segundo ele, é formada por uma noção mais "geral" ou mais "transcendental". Nesse contexto, sua compreensão do tertium comparationis é elucidativa por mostrar analogias à Hipótese da Invariância de Lakoff (1990), que corresponde à sexta hipótese de Jäkel: trata-se do esquema básico, do conteúdo invariável da palavra que continua constante em todas as ocasiões distintas em que a palavra é usada. Ora, quando Ungeheuer (1985, p.474) frisa que Lambert se refere ao significado " [...] que se retira da nomeação da palavra quanto ao mundo corporal." ${ }^{5}$, pode-se entender que isto está em sintonia com a estrutura imagética que é mantida intocada no mapeamento metafórico. Nesse ponto, em oposição a Lakoff e Johnson, a intenção de Lambert não é inaugurar uma coleção de exemplos de expressões metafóricas, mas focalizar campos semânticos inteiros para descobrir o princípio cognitivo submetido a elas, aludindo à diferença fundamental entre mundo corporal e intelectual.

Ademais, na exposição de Lambert, também já se encontra uma reflexão sobre as expressões sinestésicas que Baldauf (1997), dentro da sua revisão

\footnotetext{
No original: "Aehnlichkeit des Eindruckes, den die Empfindungen äußerlicher Dinge und die Vorstellung abstracter und unsichtbarer Dinge in uns machen."

4 No original: "Hingegen ist es schon längst eingeführt, daß wir das sichtbare mit dem unsichtbaren, die Körperwelt mit der Intellectualwelt, die Empfindungen mit den Gedanken vergleichen, und vor beyde einerley Wörter und Ausdrücke gebrauchen. Die Worte erhalten dadurch nothwendig eine doppelte und zuweilen auch vielfache Bedeutung. Ein Licht im Zimmer haben, und Licht in den Gedanken haben, sind solche Redensarten."

5 No original: "[...] die aus der Bezeichnungsweise des Wortes bezüglich der Körperwelt zu eruieren ist."
} 
da classificação das metáforas por Lakoff e Johnson, chama de "metáforas de atribuição". Lambert as concebe como tendo uma função epistemológica central por estabelecerem uma comparação entre sensações e pensamentos.

Daí, o homem chega a conclusões inteiramente analógicas como, por exemplo, a construção da bomba pneumática em analogia à bomba hidráulica. Com isso, Lambert já usa o termo da analogia junto a um exemplo similar àquele introduzido por Gentner e Gentner (1983) em seu experimento, no qual foi pedido aos participantes para explicarem o funcionamento de um circuito elétrico a partir de um interruptor de luz. Dependendo da analogia pela qual as pessoas optavam, a saber, corrente de água ou corrente de pessoas, as conclusões a que chegavam distinguiam-se: a corrente de água para assim que houver um bloqueio impedindo o fluxo contínuo, ao passo que a corrente de pessoas para assim que houver pressão e, consequentemente, um congestionamento como causa da interrupção. Na Semântica Cognitiva, encontram-se muitas referências a esse exemplo para ilustrar que a analogia pode ser definida como "comparison based on perceived similarity" (EVANS; GREEN, 2006, p.98). Kövecses (2005) realça que, no caso da analogia, tem-se um domínio-fonte e um domínio-alvo que compartilham inteiramente sua estrutura no nível genérico, de modo que podem ser caracterizados por relações estruturais semelhantes, traço que se torna crucial para a criatividade metafórica. Por fim, Kohl (2007) conclui que a analogia se trata de uma metáfora estendida, na qual o domínio-fonte se torna uma narração com sequências coerentes de sentido.

Destarte, analogias e metáforas servem para nos orientarmos no mundo cotidiano, um aspecto que, duzentos anos depois, se torna fundamental para o realismo experiencialista de Lakoff e Johnson, os quais também consideram a omnipresença da metáfora além da ferramenta intelectual:

Elas também guiam nosso funcionamento cotidiano até os detalhes mais mundanos. Nossos conceitos estruturam o que percebemos, como nos adaptamos ao mundo e como nos relacionamos com outras pessoas. Assim, nosso sistema conceitual tem um papel central na definição das nossas realidades do dia-a-dia. ${ }^{6}$ (LAKOFF; JOHNSON, 2003, p.3, tradução nossa).

Em sintonia com a noção de "Conflation" de Christopher Johnson (1999), que dedica suas pesquisas a uma fundamentação e modificação neurocientífica

6 No original: "They also govern our everyday functioning, down to the most mundane details. Our concepts structure what we perceive, how we get around in the world, and how we relate to other people. Our conceptual system thus plays a central role in defining our everyday realities."

7 A partir de uma perspectiva desenvolvimentista, com esse conceito Johnson refere-se a uma primeira fase da adquisição do pensamento metafórico, em que a criança estabelece relações entre domínios coativos, experimentando os dois campos como se um pertencesse ao outro e vice-versa. Quando a mãe responde ao 
e desenvolvimentista da TCM, Lambert (1965a, p.483), embora sem as evidências físicas às quais se tem acesso nos dias atuais, já especula que o mapeamento da metáfora tenha sua origem na paralelização das "execuções do corpo"8 e das da "razão" ao entendimento dos processos cognitivos. Sendo assim, concebemos nossa memória como contêiner, uma vez que guardamos objetos reais também em caixinhas. A ligação entre caixinha e memória resulta da "força da imaginação"10 (LAMBERT, 1965b, p.144).

Por fim, as Hipóteses da Unidirecionalidade (5), da Diacronia (4) e da Criatividade (8) revelam-se, na diferenciação que Lambert faz entre três graus da formação do significado, um construto teórico que Ungeheuer (1980) chama "tectônica semântica do vocabulário". ${ }^{11}$ Segundo tal tectônica, observa-se um desenvolvimento histórico da língua de um nível mais básico a um nível mais abstrato: (a) no primeiro nível, encontram-se palavras de raiz, como classe de objetos sensorialmente perceptíveis; (b) o segundo nível implica o uso metafórico de palavras da primeira classe e (c) o terceiro nível compreende as metáforas do metanível, que pressupõem tais do segundo grau. Neste interesse pelas mudanças e transformação do significado já é vislumbrado o princípio da polissemia e das redes radiais (radial networks) como é formulado pela TCM (LAKOFF, 1987). Por consequência, para Lambert, o motivo principal para o crescimento contínuo da língua não é o aumento do número de palavras, mas a extensão do significado original. A metáfora, em primeiro lugar, serve à "eliminação de uma carência"12 (BERTAU, 1996, p.217), por compensar a situação inicial na qual uma multiplicidade de noções se encontra de frente com um número pequeno de palavras. É este princípio econômico da língua que leva ao desenvolvimento descrito pela metaforização gradual. Contudo, concomitantemente, aumenta o perigo de mal-entendidos comunicativos (HÜLZER-VOGT, 1987), e brigas sobre palavras tornam-se mais prováveis no decorrer da primeira à terceira classe de palavras (UNGEHEUER, 1980).

pedido não verbal da filha, que aponta para um brinquedo: "Ah, estou vendo o que você quer", esta frase pode ser interpretada literalmente - a mãe vê o objeto desejado em si - ou metaforicamente, como enunciação sobre o próprio estado da consciência: ela entendeu o que a filha quer. Os domínios VER e ENTENDER são ativados simultaneamente, nos quais a cena primária compreende duas subcenas: por um lado, o ato físico da percepção, por outro lado, a mudança da consciência. Esta experiência marca o passo decisivo para a segunda fase da aprendizagem, em que o uso original da palavra se desacopla do seu emprego original, obtendo, agora, um sentido meramente metafórico.

8 No original: "Verrichtungen des Leibes"

9 No original: "Verstandes"

10 No original: "Einbildungskraft"

11 No original: "Semantische Tektonik des Wortschatzes"

12 No original: "Behebung eines Mangels" 
Com isso, além de uma antecipação da Hipótese da Ubiquidade (1) e dos Domínios (2), Lambert toca em aspectos importantes acerca da Hipótese da Focalização (9), que o trazem para o campo da comunicação - uma relação curiosamente pouco explorada pela própria TCM. Ele coloca em pauta a questão dos problemas comunicativos que surgem pelas extensões metafóricas do significado, uma vez que o falante destaca um aspecto específico do significado em um certo momento da interação, mas outro no próximo momento. Ademais, ele aponta a possibilidade de que cada indivíduo aplica a comparabilidade proclamada a aspectos diferentes, isto é, realizando uma seleção diferente da concebida pelo interlocutor. Conforme Lambert (1965b, p.183, tradução nossa), " [...] cada um pode tomar um caminho totalmente individual do pensamento para chegar a novas metáforas." ${ }^{13}$ Hülzer-Vogt (1987, p.30, grifo do autor, tradução nossa) descreve esta situação analisada por Lambert como paradoxo:

Enfrenta-se a necessidade de uma multiplicidade do significado das palavras para poder documentar e mediar reconhecimentos novos pela língua e a necessidade de uma idealização da estabilidade do

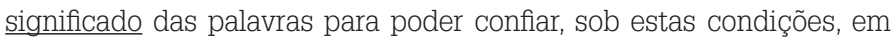
um entendimento com sucesso. ${ }^{14}$

Portanto, inconscientemente, o locutor faz idealizações que, ao mesmo tempo, atribui ao interlocutor: por um lado, a significabilidade das atribuições de significado, que Lambert (1965b, p.182-183) chama de "aprovação hermenêutica"; 15 por outro, a igualdade das atribuições de significado, o que Lambert (1965b, p.203) exprime como seu princípio "do hipotético na língua". ${ }^{16}$ Ora, convém salientar que a mesma ideia reside no Princípio de Relevância (Principle of Relevance) de Sperber e Wilson (1995), que assume a posição de que a cognição humana tem uma tendência para ser relevante. Tendhal e Gibbs (2008) mostram como as duas perspectivas, a TCM e a teoria de Sperber eWilson, são complementares, uma vez que os últimos representam uma linha cognitiva dentro da pragmática. Na visão de Sperber e Wilson (1995), a metáfora apenas apresenta uma forma do assim chamado "loose talk", por sua vez, entendido como prática cotidiana da fala cheia de vaguidades. Sendo assim, cabe ao ouvinte construir um significado contextual ao aplicar estratégias interpretativas baseadas no Princípio da Relevância e ao

13 No original: "[...] jeder sich durch ganz individuale Reihen von Gedanken, den Weg zu neuen Metaphern bähnen kann."

14 No original: "Der Notwendigkeit einer Bedeutungsvielfalt der Wörter, um neue Erkenntnisse in der Sprache erfassen und daraufhin vermitteln zu können, steht die Notwendigkeit einer Idealisierung der Bedeutungsstabilität von Wörtern gegenüber, um unter dieser Bedingung auf eine gelingende Verständigung vertrauen zu können."

15 No original: "hermeneutische Billigkeit"

16 No original: "des Hypothetischen in der Sprache" 
aplicar seu conhecimento contextual à enunciação dada. Os autores (SPERBER; WILSON, 2002, p.19-20) dão um exemplo:

Peter: Podemos confiar em John para fazer o que mandamos e defender os interesses do Departamento de Estudos Linguísticos na Comissão da Universidade?

Mary: John é um soldado. ${ }^{17}$

Ora, pode-se entender o termo "soldado" em vários sentidos: (a) John está consciente dos seus deveres, (b) John está à disposição para seguir ordens, (c) John não questiona autoridades, (d) John identifica-se com os objetivos do seu grupo, (e) John é um patriota e se pode contar com ele, (f) John recebe o salário de um soldado e ( $\mathrm{g}$ ) John é membro do exército. Todavia, por meio do esquema conhecido, apresentado por Peter ("confiar", "defender, "interesses"), Mary pode entender diretamente o que Peter quer dizer. Tais metáforas representam um fenômeno onipresente na fala cotidiana. Em oposição a outras teorias do campo pragmático, Sperber e Wilson não diferenciam entre modos distintos de compreensão no caso da metáfora em comparação a demais meios linguísticos, uma vez que cada significado puro de uma frase continua sendo subdeterminado. Nesse sentido, a teoria de Sperber e Wilson, de fato, pode ser vista como compatível e complementar à TCM, pois se dedica ao processo inferencial, aspecto descuidado por Lakoff e Johnson. Não obstante, há divergências entre as duas linhas de estudo com relação a definições básicas, como os próprios autores (SPERBER; WILSON, 2008, p.84) destacam: enquanto os linguistas cognitivos veem a metáfora como fenômeno da língua, constitutivo para a cognição humana, o foco de Sperber e Wilson está na perspectiva comunicativa dos participantes, entendendo a metáfora como algo que "emerge do processo de comunicação verbal". ${ }^{18}$ Nesse ponto, concordamos com Tendhal e Gibbs (2008), para os quais Sperber e Wilson introduzem um aspecto fundamental na discussão. Porém, a integrabilidade das duas abordagens pode ser questionada, uma vez que a perspectiva de Sperber e Wilson continua tendo o cunho das abordagens racionalistas e egológicas, modelada por uma visão instrumental, dedutiva, voltada para relevância máxima. Além disso, Sperber e Wilson partem de uma visão oposta à TCM, com relação à fundamentação e ao desenvolvimento da linguagem em si, por escolherem como ponto inicial da sua abordagem uma interligação da teoria modular de Fodor à teoria das implicaturas de Grice, seguindo o Princípio da Modularidade, que a Linguística Cognitiva busca superar.

\footnotetext{
17 No original: "Peter: Can we trust John to do as we tell him and defend the interests of the Linguistics department in the University Council? Mary: John is a soldier."

18 No original: "emerging in the process of verbal communication."
} 
Embora Lambert, ao contrário da caracterização da metáfora como loose talk na abordagem de Sperber eWilson, ainda mantenha o status especial da metáfora, dirigindo-se mais à metáfora nova do que à convencional, de modo geral os dois princípios estabelecidos por ele ilustram bem como as perspectivas funcionalista e cognitivista podem ser complementares. Ao mesmo tempo, Lambert consegue antecipar algumas premissas básicas da teoria da comunicação, a saber, o Princípio da Cooperação com suas Máximas da Conversação, como formulado por Grice (1975), ${ }^{19}$ e a Tese Geral das Perspectivas Recíprocas, com suas idealizações da "trocabilidade dos pontos de vista" e da "congruência dos sistemas de relevância", inaugurada pelo filósofo e sociólogo Alfred Schütz (1971, p.12-14), que emprestou os fundamentos fenomenológicos para a Etnometodologia e, a seguir, para a Análise da Conversação. Como Lambert afirma, especialmente o postulado da reciprocidade das perspectivas só pode ser cobrado condicionalmente, pois a comunicação continua falível. É uma consequência lógica da sua hipótese básica de que a metáfora atua como princípio fundamental na sua tectônica da língua.

\section{Philipp Wegener e sua pragmática cognitiva pioneira}

Influenciado pelo espírito da linguística histórica da época, o outsider científico Philipp Wegener (1991) descreve a metáfora como fenômeno profundamente oriundo da fala cotidiana. Ela tem uma força decisiva no desenvolvimento da língua, no qual se revela, ao mesmo tempo, seu caráter seletivo. Com esse ponto de partida, Wegener antecipa especialmente a primeira, quarta e nona hipóteses da TCM conforme descritas por Jäkel. Porém, contrariamente, Wegener escolhe uma ótica pragmática, fundamentando, já no final do século dezenove, uma teoria da comunicação concentrada na interação: "Wegener foi entre os primeiros que perceberam que falar e entender são precondicionalizados por e encaixados em ação prática e que dependem da cooperação entre os interlocutores." ${ }^{20}$ (KNOBLOCH, 1991, p.Xvi). Sendo assim, o lucro principal da sua teoria é a ponte lançada entre aspectos pragmáticos e cognitivos da língua. Daí vem a atualidade da sua abordagem. Partindo de uma perspectiva comunicativa, ele chega a

19 Aqui, estamos nos referindo apenas ao Princípio da Cooperação com suas Máximas da Conversação como contribuição e introdução valiosa de um foco voltado para a coordenação das atividades entre falante e ouvinte, aspecto ausente em conceitualizações pragmáticas anteriores. O ponto de partida de Grice são falantes e ouvintes que atuam de modo racional por seguir princípios assegurando o sucesso da comunicação. Concomitantemente, esta hipótese marca um ponto fraco da teoria, pois a influência das convenções, o a priori da racionalidade e a generalidade da socialização dos interlocutores ganham uma importância sobrestimada. $\mathrm{Na}$ concepção dele, é somente em casos excepcionais que o interlocutor se serve do contexto comunicativo, a saber, quando não consegue interpretar uma enunciação segundo seu significado "normal". Por conseguinte, a metáfora acaba recebendo um lugar marginal, sendo ela vista como mera implicatura. Com isso, Grice alicerça a separação entre semântica e pragmática, como será abordado mais para frente.

20 No original: "Wegener was among the first to realize that speaking and understanding are preconditioned by and embedded in practical action and also dependent on the cooperation among the speakers." 
questões teóricas ligadas à cognição. Nesta visão, o objetivo principal da fala sempre é a influenciação ${ }^{21}$ do ouvinte, no que diz respeito a uma certa ação, uma certa vontade ou uma certa consciência do interlocutor, sendo por essa razão que signos verbais, de modo nenhum, têm, primeiramente, função epistemológica, mas sim imperativa. Por conseguinte, Wegener começa sua abordagem com uma diferenciação de fatores contextuais distintos que assumem um papel decisivo na construção do significado no decorrer da comunicação, e que ele chama de "exposição" de uma enunciação. A ela pertencem: (a) a explicação linguística do predicado lógico, o que Wegener também entende como "exposição" no sentido mais restrito, (b) a "situação da contemplação", ${ }^{2}$ à qual pertencem as condições pessoais e temporais, (c) a "situação da recordação" ${ }^{23}$ que se refere aos acontecimentos e sequências de ações imediatamente anteriores, (d) a "situação da consciência", ${ }^{44}$ com a qualWegener identifica sistemas de significados ligados a um domínio específico, (e) por fim, a "situação cultural"25 de que fazem parte os encaixamentos geográfico e histórico de uma enunciação.

Ora, para Wegener, o processo comunicativo não pode ser definido como manifestação de uma representação verbal que seja recomposta pelo ouvinte, mas como processo da construção do significado, no qual o falante meramente disponibiliza um sistema organizado de indicações ao ouvinte, sistema o qual serve como base para o trabalho próprio do ouvinte no ato da (re)construção. Com isso, percebe-se paralelas às "pistas de contextualização" (contextualization cues) de Gumperz (1982) e à Teoria das Implicaturas de Grice (1975), uma vez que partes essenciais do significado são tiradas do que não foi dito, mas entendido. É justamente neste contexto que Wegener observa o surgimento da metáfora cognitiva, como ilustram exemplos que imediatamente lembram os trabalhos da Linguística Cognitiva: na visão de Wegener, o cotexto é responsável pela escolha de um certo domínio do nosso estoque de conhecimento que, de fato, é ativado quando ouvimos a palavra "leão", ou seja, é o campo textual que determina se o falante se refere, por exemplo, à força muscular ou à postura do leão. Isto implica que, sempre, apenas certas partes de um grupo de imaginação são ativadas, sendo aquelas que servem como exposição do predicado (WEGENER, 1991).

\footnotetext{
21 "Influenciação" - "ação ou efeito de influenciar(-se)" (HOUAISS; VILLAR, 2004) - refere-se ao termo em alemão Beeinflussung, substantivo derivado do verbo beeinflussen, cujo significado corresponde a "exercer influência sobre alguém ou alguma coisa" (DUDEN, 2011, tradução nossa), um termo que ressalta o papel de alguém que ativamente influencia o outro, ou seja, no caso da teoria de Wegener, o efeito obtido pela influenciação corresponde à vontade do falante.

22 No original: "situation der anschauung"

23 No original: "situation der erinnerung"

24 No original: "situation des bewusstseins"

25 No original: "cultursituation"
} 
Quando Wegener se dedica a uma análise da variedade dos significados dos verbos "dar" e "ter" em dependência do cotexto imediato, esta parece uma versão pragmático-semântica da noção da valência e da Gramática das Construções (GOLDBERG, 1992). "Ter dinheiro" e "ter uma ideia", para ele, ilustram a extensão metafórica do significado. Tais verbos criam expectativas no que diz respeito a complementos juntamente pensados, o que, na terminologia moderna, corresponde à ideia da ativação de slots. Somente a anulação dessas lacunas torna possível uma decisão sobre a forma como, finalmente, imaginamos o significado do verbo.

Concomitantemente, já se pode observar rastros da Semântica de Frames (FILLMORE, 2006), do realismo corporificado (LAKOFF; JOHNSON, 1980, 1999) e das noções de schema (BARTLETT, 1932; LAKOFF, 1987; JOHNSON, M., 1987), script (SCHANK; ABELSON, 1977) e scenario (SANFORD; GARROD, 1981), pois Wegener (1991, p.131, tradução nossa) é convicto de que é somente a partir da nossa "[...] experiência que surge a expectativa de um desenvolvimento do acontecimento, e daí surge o esquema da maneira como nós achamos que temos de interligar sequências de ações." ${ }^{26}$ Ele já dá a resposta da Semântica Cognitiva junto às suas hipóteses inerentes da Necessidade (7) e da Ubiquidade (1) quando começa a abordar a questão de como se pode entender a emergência de algo novo, pela ativação de esquemas e padrões de experiência via projeção analógica e comparação: " $E$ antes a língua tinha palavras desbotadas para o sujeito lógico, ela era incapaz de nomear a situação de forma diferente que pela indicação à situação presente."27 (WEGENER, 1991, p.54, tradução nossa).

Percebe-se, novamente, que os termos "metáfora", "comparação" e "analogia" são usados, muitas vezes, como sinônimos, embora entendidos por uma ótica cognitiva. Seguindo a terminologia já introduzida por Aristóteles, desde Kant $(1986,1990)$ os termos "símbolo" e "analogia" difundem-se para se referir, agora, em conformidade com a nova epistemologia cognitiva, ao mecanismo básico da construção da realidade. Sendo assim, para Kant, é pela analogia que compreendemos o estado, ou como corpo com alma, quando se refere às leis internas de um povo, ou como máquina, quando se refere a uma única vontade dominando. É nesta linha de pensamento idealista que se encaixam as abordagens sobre a metáfora das reflexões de Lambert no século dezoito, de Biese (1893), de Paul (1995) e, tendo sido influenciado por Paul, de Wegener, no final do século dezenove. Aí, surge a pergunta de se Wegener foi ou não influenciado diretamente por Lambert. Todavia, com esta abrangência de reflexões sobre a metáfora cognitiva antes da chegada de Wegener, a influência direta não seria

26 No original: "Erfahrung die Erwartung einer bestimmten Weiterentwicklung des Geschehens resultiert und daraus das Schema, wie wir Handlungsfolgen glauben verknüpfen zu müssen."

27 No original: "Und bevor die Sprache für das logische Subject abgeblasste Worte hatte, war sie unfähig, die Situation anders als durch Hinweis auf die Situation der Anschauung zu bezeichnen." 
muito provável, uma vez que Wegener, como professor do segundo grau, era um outsider científico, mais marcado pelas questões da época, a saber, pelos estudos de Paul (1995) e da Escola Alemã dos neogramáticos (Junggrammatiker). ${ }^{28}$

Ora, em abordagens atuais no campo cognitivo-discursivo, observam-se novamente cada vez mais estudos voltados para a metáfora cognitiva no seu uso atual como analogia e sua afinidade com certos gêneros comunicativos: Cameron (2008a) observa o surgimento de processos analógicos no decorrer da dinâmica da fala como mecanismo de "vehicle development", fenômeno prototípico de interações entre professores e alunos. Ela dá um exemplo em que um professor quer explicar para os alunos o fenômeno de uma erupção vulcânica, utilizando uma analogia à manteiga derretendo no micro-ondas. Schröder (2012a) revela analogias como típicas para livros atuais sobre o fim do estado social na Alemanha, para fins de ilustração. Neles, geralmente há uma analogia central como fio condutor, por exemplo a "casa da sociedade". Beckmann (2001) ilustra como anúncios de procura de parceiros para relacionamentos são muitas vezes dominados por uma analogia central. As pessoas, muitas vezes, costumam se apresentar como animais ou objetos desejados, por exemplo, carros. No campo da Análise do Discurso, Musolff (2004) e Zinken (2007) até colocam a analogia no centro da atenção de suas análises sobre discurso político. ${ }^{29}$

Os exemplos que Wegener dá provêm da fala cotidiana, compreendendo verbos com prefixos preposicionais e complementos verbais, como quando se espelha nas expressões "recuso a oferta", 30 "eu rejeito algo", 31 "eu concedo"32 ou "eu descrevo a casa oralmente"33 (WEGENER, 1991, p.136, tradução nossa), em locuções verbo-nominais (Funktionsverbgefüge), como "deixar o ponto de lado"34 (WEGENER, 1991, p.136, tradução nossa), e em descrições locais, como

28 Paul, por sua vez, integrou ideias de Wegener na segunda edição da sua obra Prinzipien der Sprachgeschichte (1995), especialmente a diferença entre o "significado usual" (no sentido do significado convencionalizado) e o "significado ocasional" (no sentido do significado que surge do contexto do uso). Foi por meio de Karl Bühler (1982) que Wegener não se tornou esquecido, pois, na sua famosa obra principal Sprachtheorie (1982), Bühler adapta alguns conceitos de Wegener. Sendo assim, por meio de Bühler, as ideias de Wegener cunharam até o contextualismo e funcionalismo britânico (Malinoswski $\Rightarrow$ Gardner $\Rightarrow$ Firth $\Rightarrow$ Halliday).

29 De certa forma, tais analogias, entendidas na terminologia de Kohl como metáforas estendidas e frequentes em gêneros discursivos específicos como discurso político ou no ensino, cumprem uma função semelhante àquela que Steen (2011) descreve quando se refere a "metáforas deliberadas" (deliberate metaphors) que se destacam por direcionar a atenção do interlocutor para sua própria metaforicidade.

30 No original: "ich weise ein Anerbieten zurück". A tradução literal do verbo seria: "puxar de volta".

31 No original: "ich lehne etwas ab". A tradução literal do verbo seria: "colocar para fora".

32 No original: "ich räume ein". A tradução literal do verbo seria: "colocar para dentro".

33 No original: "ich beschreibe das Haus mündlich"

34 No original: "den Punkt beiseite lassen" 
"no caminho da injúria"35 ou "nas vias do pecado"36 (WEGENER, 1991, p.142, tradução nossa). Tanto para Wegener como para a Semântica Cognitiva, tais expressões indicam:

[...] que, dentro de nós, existem padrões espaciais fixos, segundo os quais entendemos enunciações espaciais, e que trazemos igualmente padrões do nosso movimento no espaço para nossa alma, complementando enunciações sobre movimento, por entendê-las desse modo. ${ }^{37}$ (WEGENER, 1991, p.165, tradução nossa).

Em correspondência com a linguística alemã no final do século dezenove (PAUL, 1995), voltada para estudos sobre regularidades na história e no desenvolvimento da língua, para Wegener o mecanismo decisivo para a mudança dos significados das palavras reside na formação analógica. Portanto, ele apresenta um modelo gradual para explicar o processo do desbotamento da metáfora pelo uso constante, no qual, assim como Lakoff e Johnson, também Wegener não fala de expressões singulares, mas de grupos: "A metáfora baseiase na ligação de grupos de imaginação conforme uma igualdade parcial." ${ }^{38}$ (WEGENER, 1991, p.52, tradução nossa). Porém, expressões metafóricas como a "guerra inflama-se" 39 ou "a guerra rebenta" 40 que, em sintonia com a terminologia de Lakoff e Johnson, refletem uma metáfora conceptual como confLITO é FOGO, na visão de Wegener, para os usuários, por causa da sua convencionalização, este sentido original não é mais transparente. Como o próprio Wegener assinala, "[...] só se sente o sentido exigido pela situação, as ideias que estão ligadas adicionalmente à palavra inflamar-se, na ligação presente, são totalmente esquecidas." ${ }^{41}$ (WEGENER, 1991, p.52, tradução nossa). Aqui, como Sperber e Wilson e a própria TCM, também Wegener já antecipa uma crítica a teorias intencionalistas no campo pragmático, como as abordagens de Grice (1975) e Searle (1993). Grice distingue entre significado da sentença e significado do

35 No original: "auf dem Wege des Frevels"

36 No original: "auf den Bahnen der Sünde"

37 No original: "[...] dass feste Raummuster in unserem Inneren vorhanden sind, nach denen wir räumliche Mitteilung verstehen und dass wir ebenso Muster unserer Bewegung im Raume in unserer Seele tragen, aus denen wir Bewegungsmitteilungen ergänzen und so verstehen."

38 No original: "Die Metapher beruht auf der Verbindung von Vorstellungsgruppen nach partieller Gleichheit."

39 No original: "der Krieg entbrennt". Em alemão, a palavra entbrennen é composta pelo prefixo ent- e o verbo brennen, que significa "queimar". Sendo assim, a palavra ausbrechen, originalmente, refere-se a fogo. O verbo "rebentar" - "romper(-se), quebrar(-se) com violência; fazer(-se) em pedaços" (HOUAISS; VILLAR, 2004) aparece nos exemplos do dicionário Houaiss (2004) associado a tempestade ou chuva, mas também pode se referir a fogo, por exemplo.

40 No original: "der Krieg bricht aus"

41 No original: "[...] nur der von der Situation geforderte Sinn empfunden, die Vorstellungen, welche mit dem Worte entbrennen sonst verbunden werden, sind in dieser Verbindung total vergessen." 
enunciado de modo que a metáfora é vista como violação das Máximas da Conversação. De modo similar, na teoria da reinterpretação segundo Searle (1993), a compreensão da metáfora passa por um processo de dois passos, no qual o ouvinte (1) deriva uma interpretação literal, (2) percebe uma anomalia e, como consequência, só agora tenta aplicar uma interpretação metafórica. Esta teoria parte da suposição de que a compreensão literal é o caso não marcado, ou seja, recorrendo a Grice, Searle também distingue entre os dois sentidos que ele denomina "significado" (meaning) e "uso" (use). A metáfora, conforme Searle, pertence ao campo apelativo da intenção do falante. Nas duas abordagens, a enunciação metafórica continua sendo uma estratégia comunicativa indireta com base em cálculos monológico-racionais. Ambos, Grice e Searle, veem atos de fala como ações individuais e não sociais, uma vez que a diferença entre os dois significados apoia a suposição de uma diferença entre competência e performance e também entre semântica e pragmática. Em oposição a esta visão, no campo da linguística cognitiva, especialmente experimentos psicolinguísticos revelaram que teorias como aquela de Searle, que partem de um processo da reinterpretação, não se mantêm. Muito pelo contrário, o ouvinte não entende a metáfora passando por um processo de dois passos, mas a entende por processá-la da mesma forma que processa qualquer outra unidade lexical. Os experimentos de Hoffman e Kemper (1987) e Gibbs (1994) medem o tempo de reação para o processamento de enunciações literais e metafóricas, chegando à conclusão de que os informantes não precisaram de mais tempo para entender a expressão metafórica do que a literal. Todavia, deve-se acrescentar que essa observação, aparentemente, apenas vale para metáforas convencionais, as quais, para Searle, não seriam metáforas. Os participantes, de fato, precisam de mais tempo para interpretar metáforas novas e inovativas (GIORA, 2003).

Ora, para Wegener, o processo do desbotamento da metáfora passa por três passos (WEGENER, 1991, p.52): (a) acrescenta-se uma exposição da ideia imagética à nova expressão metafórica, por exemplo: "A guerra se inflama como um fogo"; (b) a comparação é comprimida por ser conhecida, por exemplo: "A guerra inflama-se"; (c) somente são ativadas as ideias do grupo da guerra e não mais aquelas do grupo do fogo, por exemplo: "A guerra rebenta". Com isso, Wegener já trata da comparação igualmente a Steen em sua abordagem cognitivo-textual da metáfora: enquanto Lakoff e Johnson (1999) se opõem ao entendimento da metáfora como envolvendo similaridade, Steen (2007) assinala que esta rejeição tem sua base na suposição de que tais similaridades sejam preexistentes e voltadas para substâncias ao invés de estruturas. Substituindo este conceito de similaridade por um conceito construtivista, para Steen a diferença só se reflete na superfície linguística ou no processamento psicológico, mas não na sua estrutura conceptual. Como se pode ver nesses três passos, para Wegener a diferença entre comparação e metáfora também é uma questão 
de processamento e, junto a isso, de habituação e convencionalização de forma que seu foco esteja no momento do uso.

Cabe salientar que, mais uma vez, se torna evidente que Wegener realmente está pensando em dois níveis - um nível cognitivo e um nível linguístico - ainda que isso não seja explicitado. É óbvio, uma vez que a terceira expressão desse exemplo é outra diferente daquela de (a) e (b); além disso, Wegener, concomitantemente, aponta o domínio alvo fogo que, na terminologia dele, chama-se "grupo", de modo que se pode relacionar essas proposições a uma diferenciação entre "expressão metafórica" e "metáfora conceptual".

Hülzer-Vogt (1987) trata do processo do desbotamento da metáfora nos estudos de Wegener, dirigindo sua atenção ao destaque que Wegener dá para o ouvinte: quando a metáfora ainda está ativa, ela desenvolve sua força por meio da exposição, que instrui o ouvinte quanto ao modo como ele deveria construir o imaginário da metáfora, compreendendo a situação comunicativa por inteiro. Por fim, para esse contexto comunicativo em si, Wegener realça a "sugestão" e a "simpatia" como fatores relevantes que atuam sobre o comportamento do ouvinte, conduzindo, assim, o processo da significação, pois, finalmente, é o aspecto imperativo que predomina em qualquer comunicação linguística.

Ao concluir, tocando em aspectos que ganham importância em discussões atuais dentro do cenário da teoria cognitiva da metáfora, a abordagem de Wegener deveria ser lembrada, especialmente com relação à integração da situação e do contexto na comunicação. Tais questões são elaboradas por estudos atuais, que buscam, por um lado, quebrar com a estática e artificialidade da metáfora conceptual idealizada, substituindo-a por um conceito mais dinâmico e comunicativo (CAMERON, 2007, 2008b; LINZ, 2002, 2004; GIBBS, 1999), e, por outro lado, também buscam por pesquisas crescentes no campo da relatividade cultural (KÖVECSES, 2005; ZINKEN, 2004; FERNANDEZ, 1991; SCHRÖDER, 2009, 2010b, 2012b). Destacando o papel fundamental do ouvinte, Wegener estende a base monológica da metáfora por defini-la a partir da sua função comunicativa, servindo como ferramenta voltada para uma iniciação de ações, sentimentos ou pensamentos no interlocutor. A metáfora, em primeiro lugar, serve à condução das cognições do ouvinte.

\section{Considerações finais}

Voltando para as nove hipóteses de Jäkel que comprimem as ideias-chave da TCM segundo Lakoff e Johnson, no caso de Lambert e Wegener, com base na nossa análise, pode-se chegar ao seguinte resultado, o qual já foi abordado acima: 
Quadro 1 - Antecipação das 9 hipóteses da TCM por Lambert e Wegener

\begin{tabular}{|l|c|c|c|c|c|c|c|c|c|}
\hline Precursor & $\begin{array}{c}1 . \\
\text { UBI }\end{array}$ & $\begin{array}{c}2 . \\
\text { DOM }\end{array}$ & $\begin{array}{c}3 . \\
\text { MOD }\end{array}$ & $\begin{array}{c}4 . \\
\text { DIA }\end{array}$ & $\begin{array}{c}5 . \\
\text { UNI }\end{array}$ & $\begin{array}{c}6 . \\
\text { INV }\end{array}$ & $\begin{array}{c}7 . \\
\text { NEC }\end{array}$ & $\begin{array}{c}8 . \\
\text { CRI }\end{array}$ & $\begin{array}{c}9 . \\
\text { FOC }\end{array}$ \\
\hline $\begin{array}{l}\text { Lambert } \\
(1764)\end{array}$ & $\mathrm{X}$ & $\mathrm{X}$ & {$[\mathrm{X}]^{42}$} & {$[\mathrm{X}]$} & $\mathrm{X}$ & {$[\mathrm{X}]$} & $\mathrm{X}$ & $\mathrm{X}$ & $\mathrm{X}$ \\
\hline $\begin{array}{l}\text { Wegener } \\
(1885)\end{array}$ & $\mathrm{X}$ & {$[\mathrm{X}]$} & & $\mathrm{X}$ & $\mathrm{X}$ & {$[\mathrm{X}]$} & $\mathrm{X}$ & $\mathrm{X}$ & $\mathrm{X}$ \\
\hline
\end{tabular}

Fonte: Elaboração própria.

A escolha de apresentar aqui as abordagens sobre a metáfora cognitiva de Lambert e Wegener dentro de um panorama maior de pesquisadores que já se dedicaram à metáfora cognitiva e cotidiana se deve ao mérito desses dois autores com relação a questões atualmente colocadas na pauta nas teorias cognitivas da metáfora. As contribuições de Lambert e Wegener mostram, par excellence, não apenas que as duplas perspectivas - a perspectiva cognitiva e a funcionalista, a perspectiva epistemológica e a pragmática, a perspectiva extracomunicativa e a comunicativa - são complementares, mas que elas pertencem uma à outra. A Hipótese da Focalização, também apontada, mas não profundamente explorada por Lakoff e Johnson (2003) no seu conceito do "highlighting \& hiding",43 é o elemento-chave nas duas teorias debatidas que une os dois ângulos em questão. Enquanto Lambert introduz a ótica pragmática pelo "princípio da aprovação hermenêutica", Wegener a insere pelos conceitos "exposição", "simpatia" e "sugestão". Com isso, o processo comunicativo é reparado e o ouvinte recebe um papel ativo na construção do significado em correspondência com suas próprias hipóteses e em dependência da atividade na qual ele está inserido. Assim, os dois autores vão além da mera função cognitiva e a modificam por trazê-la para o campo da interação dinâmica.

SCHRÖDER, U. A. The cognitive metaphor approach from a pragmatic standpoint in 18th and 19th centuries: the contributions of Lambert and Wegener to current discussions. Alfa, São Paulo, v.58, n.1, p.115-136, 2014.

- ABSTRACT: Since the advent of Conceptual Metaphor Theory (CMT) more than thirty years ago, many researchers have been considering that the problems of this approach is its lack of historiographical contextualization, despite the fact that the major hypotheses related to conceptual metaphor, as well as many examples, were already anticipated by philosophers, anthropologists, psychologists and linguists during the 17th century. The article introduces

42 Os colchetes significam "hipótese representada implicitamente".

${ }^{43}$ A metáfora destaca certos aspectos do seu objeto e esconde outros. 
two authors from 18th and 19th centuries - the philosopher Johann Heinrich Lambert (1965); and the linguist Paul Wegener (1991) - who, not only developed a cognitive theory of the metaphors 'we live by', but also included in their researches some pragmatic aspects which were rediscovered in recent works about cognitive metaphor and which also were characterized as issues disregarded by the first generation of CMT. Therefore, we believe that the works of Lambert and Wegener may help researchers to build a bridge from their work to current discussions, since the approaches of both scholars refer to ways of overcoming the cleavage between the solipsistic individual and the society; and they also address the dichotomy of universalism and cultural relativity. It is important to highlight that both authors concurrently understand metaphor as a cognitive and intersubjective phenomenon negotiated between participants in real communication.

- KEYWORDS: Conceptual Metaphor. Cognitive Linguistics. Pragmatics. Lambert. Wegener

\section{REFERÊNCIAS}

BALDAUF, C. Metapher und Kognition: Grundlagen einer neuen Theorie der Alltagsmetapher. Frankfurt am Main: Peter Lang, 1997.

BARTLETT, F. C. Remembering: a study in experimental and social psychology. Cambridge: Cambridge University Press, 1932.

BECKMANN, S. Die Grammatik der Metapher: eine gebrauchstheoretische Untersuchung des metaphorischen Sprechens. Tübingen: Max Niemeyer Verlag, 2001.

BERTAU, M.-C. Sprachspiel Metapher: Denkweisen und kommunikative Funktion einer rhetorischen Figur. Opladen:Westdeutscher Verlag, 1996.

BIESE, A. Die Philosophie des Metaphorischen: in Grundlinien dargestellt. Hamburg: Verlag von Leopold Voss, 1893.

BÜHLER, K. Sprachtheorie: die Darstellungsfunktion der Sprache. Stuttgart: Fischer, 1982.

Das Ganze der Sprachtheorie, ihr Aufbau und ihre Teile. In: KAFKA, G. (Org.). Bericht über den XII:Kongreß der Deutschen Gesellschaft für Psychologie in Hamburg vom 12.-16. April 1913. Jena: Gustav Fischer, 1932. p.95-122.

CAMERON, L. Metaphor shifting in the dynamics of talk. In: ZANOTTO, M. S.; CAMERON, L.; CAVALCANTI, M. C. (Org.). Confronting metaphor in use: an applied linguistic approach. Amsterdam; Philadelphia: John Benjamins, 2008a. p.45-62.

Metaphor and talk. In: GIBBS, R. W. Jr. (Org.). The Cambridge Handbook of Metaphor and Thought. Cambridge: Cambridge University Press, 2008b. p.197-211. 
Confrontation or complementarity? Metaphor in language use and cognitive metaphor theory. Annual Review of Cognitive Linguistics, La Rioja, n.5, p. 107-135, 2007.

CHAMIZO DOMINGUEZ, P. J.; NERLICH, B. Metaphor and truth in Rationalism and Romanticism. In: BURKHARDT, A.; NERLICH, B. (Org.). Tropical Truth(s): the Epistemology of Metaphor and other Tropes. Berlin; New York: De Gruyter, 2010. p.51-72.

DUDEN: Deutsches UniversalwörterbuchA-Z - 7.0. Mannheim: Dudenverlag, 2011.

EVANS, V.; GREEN, M. Cognitive Linguistics: an introduction. Edinburgh: Edinburgh University Press, 2006.

FERNANDEZ, J.W. (Org.). Beyond metaphor: the theory of tropes in anthropology. Stanford: Stanford University Press, 1991.

FILLMORE, C. J. Frame semantics. In: GEERAERTS, D. (Org.). Cognitive Linguistics: basic readings. Berlin; New York: Mouton de Gruyter, 2006. p.373-400.

GENTNER, D.; GENTNER, D. R. Flowing Waters of Teeming Crowds: Mental Models of Electricity. In: GENTNER, D.; STEVENS, A. L. (Org.). Mental Models. Hillsdale: Lawrence Erlbaum Associates, 1983. p.99-129.

GIBBS, R. W. Jr. Taking metaphor out of our heads and putting it into the cultural world. In: GIBBS, R. W. Jr.; STEEN, G. J. (Org.). Metaphor in Cognitive LinguisticS. Amsterdam; Philadelphia: John Benjamins Publishing Company, 1999. p.145-166.

. The poetics of mind: figurative thought, language, and understanding. Cambridge: Cambridge University Press, 1994.

GIORA, R. On our mind: salience, context, and figurative language. New York: Oxford University Press, 2003.

GOLDBERG, A. The inherent semantics of argument structure: the case of the English ditransitive construction. Cognitive Linguistics, Berlin, v.3, n.1, p.37-74, 1992.

GRICE, H. P. Logic and conversation. In: COLE, P.; MORGAN, J. L. (Org). Syntax and semantics. New York: Academic Press, 1975. p.41-58.

GUMPERZ, J. Discourse strategies. Cambridge: Cambridge University Press, 1982. HEIDEGGER, M. Sein und Zeit. Tübingen: Niemeyer, 1957.

HOFFMAN, R. R.; KEMPER, S. What could reaction-time studies be telling us about metaphor comprehension? Metaphor and Symbolic Activity, Santa Cruz, n.2, p.149-186, 1987. 
HOUAISS, A.; VILLAR, M. de. Dicionário Houaiss de Língua Portuguesa. Rio de Janeiro: Objetiva, 2004. Disponível em: <http://houaiss.uol.com.br/>. Acesso em: 17 dez. 2012.

HÜLZER-VOGT, H. Die Metapher: Kommunikationssemantische Überlegungen zu einer rhetorischen Kategorie. Münster: Nodus Publikationen, 1987.

HUSSERL, E. Logische Untersuchungen: Elemente einer phänomenologischen Aufklärung der Erkenntnis. Bd. 2, Zweiter Teil Halle: Max Niemeyer, 1921.

JÄKEL, O. Wie Metaphern Wissen schaffen: die kognitive Metapherntheorie und ihre Anwendung in Modell-Analysen der Diskursbereiche Geistestätigkeit, Wirtschaft, Wissenschaft und Religion. Hamburg: Kovač, 2003.

JOHNSON, C. Metaphor vs. conflation in the acquisition of polysemy: the case of SEE. In: HIRAGA, M. K.; SINHA, C.; WILCOX, S. (Org.). Cultural, typological and psychological issues in cognitive linguistics. Amsterdam: John Benjamins, 1999. p.155-169.

JOHNSON, M. The Body in the Mind: the Bodily Basis of Meaning, Imagination, and Reason. Chicago: University of Chicago Press, 1987.

KANT, I. Kritik der Urteilskraft. Herausgegeben von Karl Vorländer. Hamburg: Felix Meiner, 1990.

Kritik der reinen Vernunft. Herausgegeben von Raymund Schmidt. Hamburg: Felix Meiner, 1986.

KNOBLOCH, C. Introduction. In: WEGENER, P. Untersuchungen über die Grundfragen des Sprachlebens. Newly edited by Konrad Koerner. Amsterdam; Philadelphia: John Benjamins, 1991. p.xi-li.

KOHL, K. Metapher. Stuttgart; Weimar: Metzler, 2007.

KOLB, K. Über zwei Aspekte allen Erlebens und Erkennens. Eine historiographische Skizze eines fächerübergreifenden Problemfelds. Beiträge zur Geschichte der Sprachwissenschaft, Münster, v.20, n.1, p.65-78, 2010.

KÖVECSES, Z. Metaphor in Culture: universality and variation. Cambridge: Cambridge University Press, 2005.

LAKOFF, G. The Invariance Hypothesis: is Abstract Reason Based on ImageSchemas? Cognitive Linguistics, Berlin; New York, v.1, n.1, p.39-74, 1990.

. Women, Fire and Dangerous Things: what Categories Reveal About the Mind. Chicago: University of Chicago Press, 1987.

LAKOFF, G.; JOHNSON, M. Metaphors We Live By. Chicago: The University of Chicago Press, 2003. 
.Philosophy in the Flesh: the Embodied Mind and its Challenge to Western Thought. New York: Basic Books, 1999.

Metaphors We Live By. Chicago: the University of Chicago Press, 1980.

LAMBERT, J. H. Philosophische Schriften I: Neues Organon oder Gedanken über die Erforschung und Bezeichnung des Wahren und dessen Unterscheidung vom Irrthum und Schein. Herausgegeben von Hans-Werner Arndt. Hildesheim: Georg Olms, 1965a.

Philosophische Schriften II: Neues Organon oder Gedanken über die Erforschung und Bezeichnung des Wahren und dessen Unterscheidung vom Irrthum und Schein. Herausgegeben von Hans-Werner Arndt. Hildesheim: Georg Olms, 1965b.

LINZ, E. Sprachlose Metaphern: Zur Rhetorizität der Kognition und ihrer Modellierung in der kognitiven Linguistik. In: FOHRMANN, J. (Org.). Rhetorik: Figuration und Performanz. Stuttgart; Weimar: Metzler, 2004. p.246-266.

Indiskrete Semantik: Kognitive Linguistik und neurowissenschaftliche Theoriebildung. München: Wilhelm Fink Verlag, 2002.

MUSOLFF, A. Metaphor and political discourse: analogical reasoning in debates about Europe. Houndmills; Basingstoke: Palgrave Macmillan, 2004.

PAUL, H. Prinzipien der Sprachgeschichte. Herausgegeben von Peter Eisenberg und Helmuth Kiese. Tübingen: Max Niemeyer Verlag, 1995.

SANFORD, A. J.; GARROD, S. C. Understanding Written Language: Exploration in Comprehension Beyond the Sentence. Chichester: John Wiley, 1981.

SCHANK, R. C.; ABELSON, R. P. Scripts, Plans, Goals and Understanding: an Inquiry into Human Knowledge Structures. Hilssdale: L. Erlbaum, 1977.

SCHMITZ, H. W. Die durchgängige Tropisierung der Sprache: Über einen Aspekt von 'Zeichen im Wandel'. In: DUTZ, K. D.; SCHMITTER, P. (Org.). Historiographia Semioticae:Studien zur Rekonstruktion der Theorie und Geschichte der Semiotik. Münster: MAkS Publikationen, 1985. p.241-270.

SCHRÖDER U. Kommunikationstheoretische Fragestellungen in der kognitiven Metaphernforschung: Eine Betrachtung von ihren Anfängen bis zur Gegenwart. Tübingen: Gunter Narr, 2012a.

Applying conceptual metaphor and blending theory to culture-specific speech functions in rap lyrics. Text \& Talk: an interdisciplinary journal of language, discourse \& communication studies, Berlin; New York, n.32, p.211-234, 2012b. 
. A mesclagem metafórica de Fauconnier \& Turner e nas teorias de Karl Bühler e Wilhelm Stählin: antecipações e complementos. Revista da ABRALIN, Curitiba, n.9, p.129-154, 2010a.

Der Einfluss kultureller und kontextueller Faktoren bei der Konstruktion integrierter Netzwerke in metaphorischen blends. Zeitschrift für Angewandte Linguistik, Frankfurt am Main, n.1, p.81-102, 2010b.

Preferential Metaphorical Conceptualizations in Everyday Discourse About Love in the Brazilian and German Speech Communities. Metaphor and Symbol, Santa Cruz, v.24, n.2, p.105-120, 2009.

. Antecipações da metáfora cotidiana nas concepções de Hans Blumenberg e Harald Weinrich. Revista de Estudos da Linguagem, Belo Horizonte, v.16, n.2, p.39-54, 2008.

Os precursores filosóficos da teoria cognitiva das metáforas. Cadernos de Estudos Lingüísticos, Campinas, v.46, n.2, p.243-252, 2004.

SCHÜTZ, A. Gesammelte Ausätze I: Das Problem der sozialen Wirklichkeit. Den Haag: Martinus Nijhoff, 1971.

SEARLE, J. R. Metaphor. In: ORTONY,A. (Org.). Metaphor and Thought. Cambridge: Cambridge University Press, 1993.

SPERBER, D.; WILSON, D. A Deflationary Account of Metaphors. In: GIBBS, R. W. Jr. (Org.). The Cambridge Handbook of Metaphor and Thought. Cambridge: Cambridge University Press, 2008. p.84-105.

Pragmatics, modularity, and mind-reading. Mind \& Language, London, n.17, p.3-23, 2002.

Relevance: Communication and Cognition. Oxford: Blackwell, 1995.

STEEN, G. J. From three dimensions to five steps: the value of deliberate metaphor. metaphorik.de, Essen, n.21, p.83-110, 2011.

STEEN, G. J. Finding Metaphor in Grammar and Usage. Amsterdam: John Benjamins, 2007.

TENDHAL, M.; GIBBS, R. W. Jr. Complementary Perspective on Metaphor: Cognitive Linguistics and Relevance Theory. Journal of Pragmatics: an Interdisciplinary Journal of Language Studies, Lancaster, n.40, p.1823-1864, 2008.

UNGEHEUER, G. Kommunikative und extrakommunikative Betrachtungsweisen in der Phonetik. In:UNGEHEUER, G. Sprache und Kommunikation. Herausgegeben von Karin Kolb und H. Walter Schmitz. Münster: Nodus Publikationen, 2004. p.22-34. 
Prinzipien strukturaler Wortfeldanalyse bei Lambert. In: ÖLBERG, H. M.; SCHMIDT, G. (Org.). Sprachwissenschaftliche Forschungen. Festschrift für Johann Knobloch. Innsbruck:Verlag des Instituts für Sprachwissenschaft der Universität Innsbruck, 1985. p.473-479.

Lamberts semantische Tektonik des Wortschatzes als universales Prinzip. In: BRETTSCHNEIDER, G.; LEHMANN, C. (Org.). Wege der Universalienforschung. Sprachwissenschaftliche Beiträge zum 60. Geburtstag von Hansjakob Seiler. Tübingen: Gunter Narr, 1980. p.87-93.

Über das "Hypothetische in der Sprache" bei Lambert. In: BÜLOW, E.; SCHMITTER, P. (Org.). Integrale Linguistik. Festschrift für Helmut Gipper. Amsterdam: John Benjamins, 1979. p.69-98.

WEGENER, P. Untersuchungen über die Grundfragen des Sprachlebens. Wiederherausgegeben von Konrad Koerner. Amsterdam: John Benjamins, 1991.

ZINKEN, J. Discourse metaphors: the link between figurative language and habitual analogies. Cognitive Linguistics, Berlin, v.18, n.3, 2007, p.445-466.

. Metaphors, stereotypes, and the linguistic picture of the world: Impulses from the Ethnolinguistic School of Lublin. Imetaphorik.de, Frankfurt am Main, n.7, 2004. p.115-136. Disponível em: <http://www.metaphorik.de/07/zinken.pdf>. Acesso em: 9 out. 2012.

Recebido em outubro de 2012.

Aprovado em janeiro de 2013. 